\title{
The Swedish childhood diabetes study: indications of severe psychological stress as a risk factor for Type 1 (insulin-dependent) diabetes mellitus in childhood
}

\author{
B. Hägglöf ${ }^{1}$, L.Blom ${ }^{3}$, G. Dahlquist ${ }^{3}$, G. Lönnberg ${ }^{2}$ and B.Sahlin $^{1}$ \\ ${ }^{1}$ Department of Child Psychiatry and ${ }^{2}$ the Department of Epidemiology and Health Care Research, University of Umeå, Umeå; \\ ${ }^{3}$ Department of Paediatrics, Karolinska Institute, Sachs' Children's Hospital, Stockholm, Sweden
}

\begin{abstract}
Summary. This study is part of a nationwide case-referent study. All recent-onset Type 1 (insulin-dependent) diabetic children aged 0-14 years in Sweden were invited to participate. Referent subjects matched for age-, sex- and geographical distribution were selected. In all, 338 patients and 528 referent subjects took part. Life events during the last year prior to clinical onset of Type 1 diabetes were recorded on a questionnaire. The total frequency of life events did not differ between diabetic and referent children. However, qualitatively the life events reported by diabetic children revealed a tendency to increased severity. Events related specifically to actual or threatened losses within the family - events that may affect children differently in different age groups - were reported with a significantly higher frequency by diabetic pa-
\end{abstract}

tients than by referent subjects, aged 5-9 years. The relative risk that such events in fact comprise a risk factor for Type 1 diabetes was 1.82 (95\% confidence limits $1.09,3.03)$. The relative risk was significantly increased even when standardized for possible confounding factors such as age, sex and indices of social status of the family. We conclude that stressful life events, related to actual or threatened losses within the family, occurring in the vulnerable age group of 59 years, are associated with the onset of childhood Type 1 diabetes. Such stressful events may in fact be a risk factor for the disease.

Key words: Type 1 (insulin-dependent) diabetic children, psychological stress, disease onset.
Studies on the aetiology of Type 1 (insulin-dependent) diabetes suggest that certain immunogenic mechanisms predispose to an increased risk of developing Type 1 diabetes from environmental factors $[1,2]$. Among environmental factors viral infections $[3,4]$, dietary habits $[5-7]$, toxic agents $[8,9]$ and even emotional stress [10-12] have been proposed as possible triggering mechanisms.

Clinical and experimental studies have shown that psychosocial stress may affect immune function in a variety of ways $[13,14]$. Furthermore, emotional stress increases the levels of the counter-regulatory hormones - catecholamines, growth hormones and cortisol - thus increasing the peripheral need for insulin [15].

Thus, it is of interest to examine whether epidemiological evidence also implicates psychosocial stress as a risk factor for Type 1 diabetes.

In a large population-based case-referent study we examined reported life events during a one-year period prior to the onset of Type 1 diabetes in childhood.

The following questions were analysed:

- Are the total number of life events a risk factor for Type 1 diabetes in childhood?

- Is there an association between the quality of life events and the risk for Type 1 diabetes in childhood?
- Will life events affect the risk for developing Type 1 diabetes differently in different age groups?

\section{Subjects and methods}

This study is part of a nationwide Swedish case-referent study focussing on different aetiological aspects of Type 1 diabetes. The study design and data collection procedure have been reported earlier in detail $[16,17]$. During a one-year period all recent-onset Type 1 diabetic patients in Sweden age 0-14 years were invited to participate in the study. Two referent subjects, matched for age-, sexand geographical distribution were selected for each patient, using the official Swedish population register (SPAR-DAFA). Of the patients $86 \%$ (338 of 393) and of the referent subjects 69\% (528 of 786) entered the study. Analysis of the dropout subjects revealed no differences regarding age, sex and place of residence compared to the participants. Family characteristics such as marital status of parents, parental age, number of siblings, proportion of immigrants were similar in the diabetic families and in the referent families [17]. A questionnaire was submitted approximately 4 weeks after diagnosis of Type 1 diabetes to the patient's family at the same time as to the two referent families. To avoid primary recall bias, the specific focus on diabetes was not mentioned in the introductory letter.

The life events section of this questionnaire consisted of 45 events that might have occurred within the family during the past year (Table 1). The inventory was modified after a previous life 
Table 1. Life event scores (LCU) by age group

\begin{tabular}{|c|c|c|c|}
\hline \multirow[t]{2}{*}{ Life events } & \multicolumn{3}{|c|}{ Age (years) } \\
\hline & $0-4$ & $5-9$ & $10-14$ \\
\hline 1. Birth or adoption of a brother or sister & 50 & 50 & 50 \\
\hline 2. ${ }^{a}$ Serious illness or injury of the mother & 51 & 55 & 54 \\
\hline 3. Loss of job by a parent & 23 & 38 & 48 \\
\hline 4. ${ }^{\text {a }}$ Serious illness or injury of the father & 51 & 55 & 54 \\
\hline $5 .^{a}$ Death of the mother & 89 & 91 & 94 \\
\hline 6. ${ }^{\mathrm{a}}$ Marital separation of the parents & 74 & 78 & 77 \\
\hline 7. Jail sentence of parent & 50 & 55 & 63 \\
\hline 8. Hospitalization of the child & 59 & 62 & 59 \\
\hline 9. Addition of a third adult to the family & 39 & 41 & 34 \\
\hline 10. Change in parents' financial status & 21 & 29 & 40 \\
\hline 11. Death of the father & 89 & 91 & 94 \\
\hline 12. Serious illness or injury of a sibling & 37 & 41 & 44 \\
\hline 13. ${ }^{a}$ Brother or sister leaving home & 39 & 36 & 33 \\
\hline 14. Mother married to a step-parent & 62 & 65 & 63 \\
\hline 15. Father married to a step-parent & 62 & 65 & 63 \\
\hline 16. The family moves to another place & $\mathrm{b}$ & $\mathrm{b}$ & \\
\hline 17. Discovery of being an adopted child & 33 & 52 & 70 \\
\hline $18 .^{a}$ Divorce of parents & 78 & 84 & 84 \\
\hline 19. ${ }^{\text {D }}$ Death of a brother or sister & 59 & 68 & 71 \\
\hline 20. Hospitalization of the father & 51 & 55 & 54 \\
\hline 21. Mother beginning to work & 47 & 44 & 36 \\
\hline 22. ${ }^{a}$ Death of a grandparent & 30 & 38 & 35 \\
\hline 23. Death of a close friend to the child & 38 & 53 & 65 \\
\hline 24. The family changes apartment/house & $\mathrm{b}$ & b & b \\
\hline 25. Hospitalization of the mother & 51 & 55 & 54 \\
\hline 26. ${ }^{\mathrm{a}}$ Hospitalization of a brother or sister & 37 & 41 & 44 \\
\hline 27. Beginning the pre-school year & 42 & - & - \\
\hline 28. Change pre- or nursery school & 33 & - & - \\
\hline 29. Change of "nursery-mother" & 33 & - & - \\
\hline 30. Beginning $1^{\text {st }}$ year of compulsory education & 42 & - & - \\
\hline 31. Change to a different class or school & 33 & 46 & 52 \\
\hline 32. Father beginning to work & 36 & 45 & 42 \\
\hline 33. Decrease in arguments between parents & 21 & 25 & 29 \\
\hline 34. Increase in arguments between parents & 44 & 51 & 48 \\
\hline 35. Decrease in arguments with parents & 22 & 27 & 29 \\
\hline 36. Increase in arguments with parents & 39 & 47 & 46 \\
\hline 37. Outstanding personal achievement & 23 & 39 & 45 \\
\hline 38. Beginning $7^{\text {th }}$ year of compulsory education & - & - & 45 \\
\hline 39. Failure of a year in school & - & 57 & 62 \\
\hline 40. Menarche & $b$ & $\mathrm{~b}$ & \\
\hline 41. Unwed pregnancy & - & - & 95 \\
\hline 42. Fathering an unwed pregnancy & - & - & 76 \\
\hline 43. Abortion & b & b & b \\
\hline 44. Breaking up with a boy- or girlfriend & - & - & 47 \\
\hline 45. Serious illness or injury of the child & 59 & 62 & 59 \\
\hline
\end{tabular}

a Life events including losses or threatened losses in the family.

b LCU not available. - Not relevant for the age group

event questionnaire developed and evaluated by Coddington [18, 19] and Hurme [20]. Items No. 8 and 45 were excluded in the analyses since the patients tended to regard the onset of diabetes itself as a "hospitalization" and "serious illness" event.

Three different methods were used for qualitative evaluation of the life events.

First the severity of life events was classified according to the life change values (LCU) defined by Coddington [19]. Coddington's values were based on the judgements of paediatricians, teachers and child psychologists. Later studies by Hurme [20] and by Monaghan et al. [21] confirmed the general applicability of the LCU scale for evaluating the severity of life events.

Second, each family evaluated "how upsetting" the occurred life event was to the child on a self-esteem analogue scale (SE) (range 0100), previously used by Cederblad and Höök [22]. "Severe life events" were defined either as LCU level $>50$ or SE level $>50$ respectively.
Third, losses within the family have previously been reported as being associated with the onset of diabetes in both children and adults [23-25]. Therefore, we analysed separately those life events involving actual or threatened losses within the family (items No.2, $4,5,6,7,11,12,13,18,19,20,22,25,26$ and 43 of Table 1$)$.

As life events may affect children in different ways in different age groups, all analyses were performed separately in children 0-4, 5-9 and $10-14$ years.

The study was approved by the Ethics Committee at the Karolinska Institute as well as by the Swedish Data Inspection Board. Informed consent was received from all families.

\section{Statistical analysis}

Matching proved unnecessary since the ratio between the relative risk from matched and unmatched data for important associations was close to one [26]. The Chi-squared test was used when comparing frequencies. Relative risks were calculated as odds ratios and $95 \%$ confidence intervals according to Miettinen [27]. To control for possible confounding factors standardized risk ratios (SRR) and 95\% confidence intervals were calculated. The analyses were performed using the Quest Software developed by L. Gustavsson, University of Umeå, Sweden.

\section{Results}

\section{Quantitative estimates of life events}

The relative frequency of the number of experienced life events during the last year for diabetic and referent children respectively are given in Figure 1. Nearly half of the children had experienced more than one event. No differences existed between the two groups. The mean number of life events was 1.9 for both diabetic and referent children. Furthermore, breakdown analysis into three age groups $(0-4,5-9,10-14)$ failed to reveal any significant differences between diabetic and referent subjects (Table 2).

Table 2. Mean frequencies of life events in diabetic and referent children in different age groups, figures within brackets denote the number of life events

\begin{tabular}{lllll}
\hline & $0-4$ years & $5-9$ years & $10-14$ years & Total \\
\hline Diabetic children & $n=70$ & $n=116$ & $n=152$ & $n=338$ \\
$(n=338)$ & $1.7(121)$ & $2.1(248)$ & $1.7(259)$ & $1.9(628)$ \\
Referent children & $n=118$ & $n=165$ & $n=245$ & $n=528$ \\
$(n=528)$ & $1.8(212)$ & $1.9(313)$ & $1.9(456)$ & $1.9(981)$ \\
\hline
\end{tabular}

Table 3. Mean levels of life change estimation by use of $\mathrm{SE}^{\mathrm{a}}$ and $\mathrm{LCU}^{\mathrm{b}}$

\begin{tabular}{lll}
\hline & $\begin{array}{l}\text { Diabetic children } \\
n=338\end{array}$ & $\begin{array}{l}\text { Referent children } \\
n=528\end{array}$ \\
\hline $\mathrm{SE}^{\mathrm{a}}$ & x SD Range & x SD Range \\
& $56(95,0-800)$ & $54(82,0-530)$ \\
LCU $^{\text {b }}$ & $69(86,0-665)$ & $66(74,0-481)$ \\
\hline
\end{tabular}

${ }^{\text {a }}$ Self esteem scores [22]; ${ }^{b}$ LCU according to Coddington $[18,19]$ and Hurme [20] 


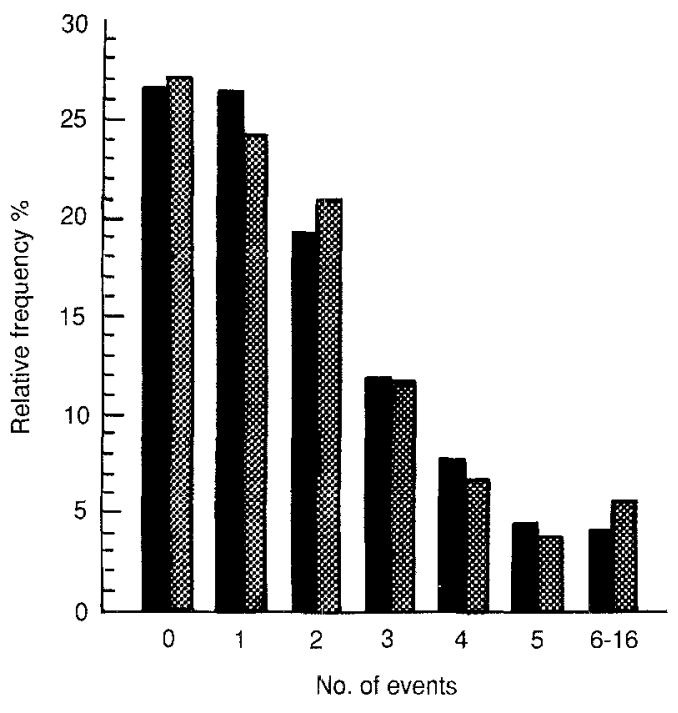

Fig.1. Relative frequency of all life events among diabetic and referent children $0-14$ years. Diabetic children; Referent children

\section{Qualitative estimates of life events}

Table 3 shows the means, standard deviations and ranges of the life events classified according to the self esteem (SE) and life change units (LCU) systems, respectively. No significant differences were seen between the diabetic and referent subjects. The number of severe life events as determined on the SE scale (SE > 50) tended to be higher among the diabetic children, but the difference was not statistically significant. The mean frequency of life events related to actual or threatened losses also tended to be higher in the diabetic compared to the referent children $(0.45$ vs $0.36, p=0.08)$ as illustrated in Figure 2.

Table 4. Relative risk estimated as odds ratio of developing Type 1 (insulin-dependent) diabetes when exposed to life events including losses within the family

\begin{tabular}{cllc}
\hline Age group (years) & OR estimate & \multicolumn{2}{l}{$95 \%$ confidence limits } \\
\hline $0-4$ & 1.05 & 0.51 & 2.17 \\
$5-9$ & 1.82 & 1.09 & 3.03 \\
$10-14$ & 0.94 & 0.59 & 1.50 \\
\hline $0-14$ & 1.19 & 0.88 & 1.62 \\
\hline
\end{tabular}

Table 5. Relative risk of developing Type 1 (insulin-dependent) diabetes in 5-9 year-old children when exposed to life events including severe losses within the family. Crude values and values standardized for different confounding factors. Mantel-Haenszel rate ratio is given

\begin{tabular}{lllc}
\hline & \multicolumn{2}{l}{ Odds ratio } & \multicolumn{2}{l}{$95 \%$ confidence limits } \\
\hline Crude & 1.82 & 1.09 & 3.03 \\
Standardized for & & & \\
$\quad$ age & 1.81 & 1.08 & 3.05 \\
$\quad$ sex & 1.82 & 1.09 & 3.03 \\
maternal age & 1.75 & 1.05 & 2.92 \\
$\quad$ maternal education & 1.85 & 1.11 & 3.09 \\
$\quad$ Type 1 diabetes among & & & \\
1st degree relatives & 1.84 & 1.12 & 3.11 \\
\hline
\end{tabular}

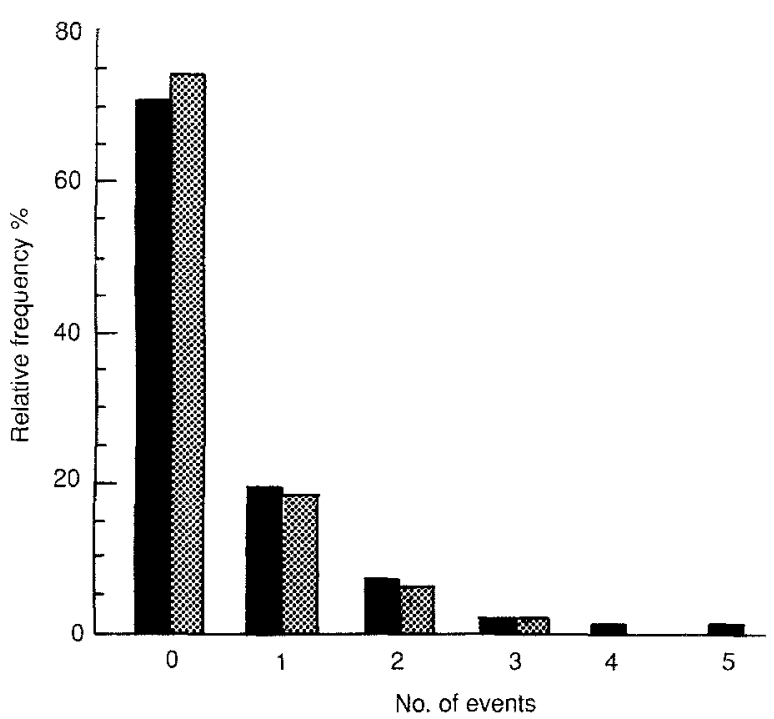

Fig.2. Relative frequency of actual or threatened losses among diabetic and referent children $0-14$ years. Diabetic children; Referent children

\section{Qualitative estimates of life events in different age groups}

Life events related to losses within the family differed among the different age groups. In the 5-9 year age group the frequency of such events was higher among Type 1 diabetic than among referent children, as illustrated in Figure 3. Likewise the odds ratio that such events comprise a risk factor for Type 1 diabetes was significantly higher among children of 5-9 years (Table 4). This increased risk was still significant when standardized for possible confounding factors such as age, sex, maternal age and education, and the existence of Type 1 diabetes among first-degree relatives (Table 5).

A similar discrepancy in odds ratios regarding the SE qualitative measure was found among the three different age groups, i. e. $0-4$ years $\mathrm{OR}=0.88,5-9$ years $\mathrm{OR}=1.48$ and $10-14$ years $O R=1.17$. However, confidence limits for the age group 5-9 years, included 1.0. The Coddington $\mathrm{LCU}$ index revealed no such age differences.

\section{Discussion}

In this large population-based case-referent study, recentonset Type 1 diabetic children were compared with healthy referent children. No differences were found between the two groups in the total frequency of experienced life events during the year prior to the onset of diabetes. However, the frequency of life events that included actual or threatened losses within the family events assumed to be very stressful for children - was significantly higher among diabetic than among referent children in the age group 5-9 years.

This age group could be especially vulnerable to the influence of stressful life events due to the discrepancy between cognitive skills and actual emotional development [28]. According to recent epidemiological studies, certain child psychiatric symptoms also show peak incidences in 


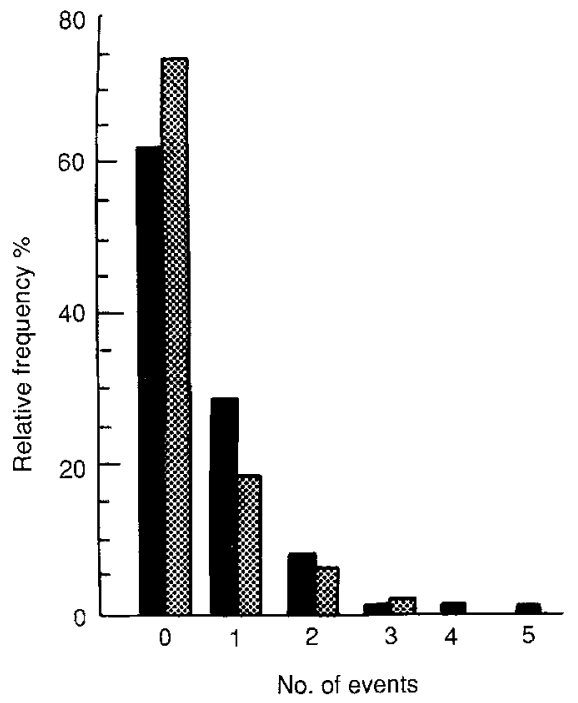

Fig.3. Relative frequency of actual or threatened losses among diabetic and referent children 5-9 years. Diabetic children; Referent children

this age group $[29,30]$. Alternatively, it may simply be that some separation traumas, e.g. parental divorce, are more common for children at this age [31].

Another interpretation of the lack of significant association between psychological stress and Type 1 diabetes in the youngest and oldest age groups studied might just be explained by the possibility that other risk factors are prevailing in those age groups, to mask the role of stress.

The frequency of severe life events, as determined by the self esteem (SE) scale, was also higher, though not statistically significant among diabetic children, especially in the age group 5-9 years. On the other hand, severe life events as measured on the LCU scale did not differ between the two groups. This discrepancy could be due to the low rating scores $(<50)$ that certain items connected with family losses receive on Coddington's LCU scale [18, 19].

The present study suggests that severe psychological stress may be a risk factor for childhood Type 1 diabetes. The pathophysiological mechanism behind this finding is speculative. An increase in peripheral insulin requirements due to stress-induced increases in counter-regulatory hormones (i. e. catecholamines, growth hormone and glucagon) could be one possible mechanism. Stressful events would serve as a promoting factor, turning a prediabetic state into overt Type 1 diabetes. This hypothesis is in agreement with two recent animal studies $[11,12]$. Alternatively, severe stress could influence the autoimmune destruction of the Beta cells. The adrenocortropic hormone-stimulated cortisol effect on immunologic processes could be of importance in this process [13]. The immune function is modulated by psychological stress in various ways [14].

As early as 1684 Thomas Willis stated that diabetes was related to "prolonged sorrow" [32]. Some decades later a "diabetic personality", at increased risk of developing Type 1 diabetes, was suggested [33,34]. During the last decades, research has focussed on the occurrence of stressful life events prior to the clinical onset of Type 1 diabetes [23-25, 35-41]. Results of these life event studies, however, are contradictory.

A host of methodological problems complicates any serious evaluation of previous life event studies. Very divergent study designs have been employed. Likewise, different methods have been used for assessing both the types and the qualities of life stress. Furthermore, patients have been very heterogeneous with regard to ages and to selection methods. As a rule the samples have been small, i. e. ranging from 3 to 38 cases. In some of the studies no referent groups were used at all, in others referent subjects were not selected at random from the general population. Given these overwhelming methodological differences it is not surprising that the results from these studies are strongly divergent. Several studies, such as our own, fail to show an overall increase in the frequency of life events prior to the onset of Type 1 diabetes. At the same time, a number of previous studies (and even our own) indicate that severe life events - specifically events including losses in the family - are associated with Type 1 diabetes in childhood [23-25]. In three recent studies other qualitative measurements likewise revealed increased life stress in children prior to the onset of Type 1 diabetes [36-38].

Finally, a number of potential methodological biases in our own study must be critically examined. As in all casereferent studies it could be suspected that patients respond differently than non-patients. Specifically, that parents of a diabetic child, seeking an explanation for their child's illness, might tend to remember a greater number of life events than parents of a healthy child. The results, however, showed no differences in the number of reported events. On the other hand, severe life events, such as actual or threatened loss within the family, are less likely to be forgotten even in families with a healthy child. Thus, the reported differences are very likely real.

There was a higher number of dropouts among the referent families compared to the diabetic families. The age, sex and geographical distribution, however, was similar between both dropouts and participants.

It could be suspected that families with either low or with high social status might be over-represented among dropouts. However, the increased relative risk for Type 1 diabetes was similar when standardized for maternal education, an important social determinant for child health.

The present study indicates that severe emotional stress, induced by actual or threatened loss within the family, is associated with the onset of childhood diabetes, in the age group 5-9 years.

Further evaluation is required to determine whether severe psychosocial stress several years prior to clinical onset of Type 1 diabetes may also play a pathophysiological role. Likewise, further experimental studies are needed to determine the exact pathophysiological mechanisms behind severe stress as a risk factor for Type 1 diabetes in children.

Acknowledgements. This work was supported by grants from the Swedish Medical Research Council, Project No07531, The Commission for Social Research, Project No F 89/140:1, Swedish Ministry 
of Heaith and Social Affairs, the Swedish Diabetes Association, the Medical Faculty of Umeå, Sweden, Nordisk Insulinfond and First of May Flower Annual Campaign for Childrens Health.

\section{References}

1. Bottazzo GF, Pujol-Borrell R, Gale E (1985) Etiology of diabetes: the role of autoimmune mechanisms. In: Alberti KGMM, Krall LP (eds) The diabetes annual. Elsevier, NorthHolland, pp 16-52

2. Lernmark $\AA$ (1985) Molecular biology of Type 1 (insulin-dependent) diabetes mellitus. Diabetologia 28: 195-203

3. Yoon J-W, Austin M, Onodera T, Notkins AL (1979) Virus-induced diabetes mellitus. Isolation of a virus from the pancreas of a child with diabetic ketoacidosis. N Engl J Med 300: 1173-1179

4. Notkins AL, Yoon J-W (1984) Virus-induced diabetes mellitus. In: Notkins AL, Oldstone MBA (eds) Concepts in viral pathogenesis. Springer, New York, pp 241-247

5. Borch-Johnsen K, Joner G, Mandrup-Poulsen T et al. (1984) Relation between breast-feeding and incidence rates of insulin-dependent diabetes mellitus. A hypothesis. Lancet II: 1083-1086

6. Elliott RB, Martin JM (1984) Dietary protein: a trigger of insulin-dependent diabetes in the BB rat? Diabetologia 26: 297299

7. Dahlquist G, Blom L, Persson L- $\AA$, Sandström A, Wall S (1990) Indications of nutritional risk determinants for diabetes in childhood. Br Med J 300: 1302-1306

8. Helgason T, Ewen SW, Ross IS, Stowers JM (1982) Diabetes produced in mice by smoked/cured mutton. Lancet II: 1017-1022

9. Toniolo A, Onodera T, Yoon J-W, Notkins AL (1980) Induction of diabetes by cumulative environmental insulitis from viruses and chemicals. Nature 288: 383-385

10. Danowski TS (1963) Emotional stress as a cause of diabetes mellitus. Diabetes 12: 183-184

11. Carter WR, Herrman J, Stokes K, Cox DJ (1987) Promotion of diabetes onset by stress in the BB rat. Diabetologia 30: 674-675

12. Mazelis AG, Albert D, Crisa C et al. (1987) Relationship of stressful housing conditions to the onset of diabetes mellitus induced by multiple, sub-diabetogenic doses of streptozotocin in mice. Diabetes Res 6: 195-200

13. Bateman A, Singh A, Kral T, Solomon S (1989) The immune-hypothalamic-pituitary adrenal axis. Endocrinol Rev 10:92-112

14. Palmblad J (1981) Stress and immunologic competence: Studies in man. Psychoneuroimmunology. In: Ader R (ed). Academic Press, New York, pp 229-257

15. Turkkan JS, Brady JV, Harris AH (1982) Animal studies of stressful interactions: a behavioral-physiological overview. In: Goldberger L, Brezhitz S (eds) Handbook of stress. The Free Press, New York, pp 153-182

16. Dahlquist G, Blom L, Tuvemo T, Nyström L, Sandström A, Wall S (1989) The Swedish childhood diabetes study - Results from a nine year case register and a one year case-referent study indicating that Type 1 (insulin-dependent) diabetes mellitus is associated with both Type 2 (non-insulin-dependent) diabetes mellitus and autoimmune disorders. Diabetologia 32:2-6

17. Blom L, Dahlquist G, Nyström L, Sandström A, Wall S (1989) The Swedish childhood diabetes study. Social and perinatal determinants for diabetes in childhood. Diabetologia 32: 7-13

18. Coddington RD (1972) The significance of life events as etiologic factors in the disease of children. I. A survey of professional workers. J Psychosom Res 16: 7-18

19. Coddington RD (1972) The significance of life events as etiologic factors in diseases of children. II. A study of a normal population. J Psychosom Res 16: 205--213
20. Hurme H (1983) Life events in children. J Social Med (In Swedish) 4-5:246-253

21. Monaghan JH, Robinson JO, Dodge JA (1979) The children's life events inventory. J Psychosom Res 23: 63-68

22. Cederblad M, Höök B (1978) Daycare for three-year-olds - an interdisciplinary experimental study. V. Laboratory for Clinical Stress Research, Stockholm, No 79

23. Slawson PF, Flynn WR, Kollar EJ (1963) Psychological factors associated with the onset of diabetes mellitus. JAMA 185: 166170

24. Stein SP, Charles ES (1971) Emotional factors in juvenile diabetes mellitus. Am J Psychiat 128: 700-704

25. Leaverton DR, White CA, McCormick CR, Smith P, Sheikholislam B (1980) Parental loss antecedent to childhood diabetes mellitus. J An Acad Child Psychiat 19:678-689

26. Miettinen O (1972) Components of the crude risk ratio. Am J Epidemiol 96: 168-172

27. Miettinen $\mathrm{O}$ (1976) Estimability and estimation in case-referent studies. Am J Epidemiol 103: 226-235

28. Piaget J (1966) The psychology of the child. Presses universitaires de France, Paris

29. Bird HR, Canino G, Rubio-Stipec M, Ribera JC (1988) Estimates of the prevalence of childhood maladjustment in a community survey in Puerto Rico. Arch Gen Psychiatry 45: 1120 1126

30. Lagerheim B (1988) Preparing disabled children for coping with adolescent stress. Int J Adolescent Med Health 2: 309-316

31. Childrens' living conditions (1989) Official statistics of Sweden. National central bureau of statistics, Stockholm

32. Willis T (1684) Practice of physick: Treatise II. Pharmacentice Rationalis. Dring, Hayer \& Leigh, London, p74

33. Dunbar F (1954) Emotions and bodily changes. Columbia University Press, New York

34. Johnson SB (1980) Psychosocial factors in juvenile diabetes: A review. J Behav Med 3: 95-116

35. Hinkle LE, Evans FM, Wolf S, Conger G, Edwards CJ, Pugh BL (1951) Studies in diabetes mellitus. IV. Life history of three persons with relatively mild, stable diabetes and relation of significant experiences in their lives to the onset and course of the disease. Psychosom Med 13: 184-202

36. Robinson N, Fuller JH (1985) Role of life events and difficulties in the onset of diabetes mellitus. J Psychosom Res 29: 583-591

37. Vialettes B, Ozanon JP, Kaplansky S et al. (1989) Stress antecedents and immune status in recently diagnosed Type I (insulindependent) diabetes mellitus. Diab Metab 15: 45-50

38. Robinson N, Lloyd CE, Fuller JH, Yateman NA (1989) Psychosocial factors and the onset of Type 1 diabetes. Diab Med 6: 5358

39. Grant I, Kyle GC, Teichman A, Mendels J (1974) Recent life events and diabetes in adults. Psychosom Med 36: 121-128

40. Koch M, Molnar G (1974) Psychiatric aspects of patients with unstable diabetes mellitus. Psychosom Med 36: 57-68

41. Kovacs M, Feinberg TL, Paulauskas S, Finkelstein R, Pollock M, Crouse-Novak M (1985) Initial coping responses and psychosocial characteristics of children with insulin-dependent diabetes mellitus. J Pediatr 106: 827-834

Received: 2 November 1990

and in revised form: 10 April 1991

Dr. B. Hägglöf

Department of Child Psychiatry

University of Umeå

S-90187 Umeå

Sweden 